Elaine Humphrey: I had that kind of competition as well when I first took over, but what we did was to get all the lab managers together for a networking session. So if Mary over in Materials had somebody who wanted to look at bacteria, shed send them over to me. I don't have an EDX on anything except the variable pressure scopes and we don't use it so often. So when people come to me once every two or three years for EDX, I send them over to Mary. She's the one with the expertise in it. We work really well together.

\section{Part Ib: How to Make a Business Plan for Facility Maintenance and Growth.}

\section{Donald A. Blewett \\ Burton D. Morgan Center for Entrepreneurship, Purdue University}

In case you didn't realize it, one of the things that is important about a business plan is to have an enthusiastic champion. I don't know if I've seen a person that has represented what she does more enthusiastically than Elaine did just now.

One of the reasons why I asked Elaine to go first was there's a lot of preparatory work that goes in place before you put together a business plan. Elaine did a very nice job in planning, and one of the key things in her Strategic Plan was that she took planning and made it a part of the business plan. A "S.W.O.T." Analysis is an exercise that you go through when you are dealing with an enterprise that talks about Strengths, Weaknesses, Opportunities and Threats. Elaine put together the S.W.O.T. Analysis in addition to the current facility description and wish lists and that was extremely helpful in putting together her business plan.

You will be writing a business plan for an audience and there are a lot of audiences-associates and colleagues, employees, senior management (no matter who you are or where you are, you all have senior management to deal with), suppliers and vendors (again, if you are working closely with people who are involved in your enterprise, suppliers and vendors would be extremely important), talented people and potential strategic collaborators. They want to know what you're about; they want to know what you're doing, and this is the opportunity for you to tell them. Not to be flip about it, but every once in a while you may lose direction on what you want to do, on what you are trying to accomplish. So your business plan that you're putting together is very likely going to be as much for yourself as it is for anybody else.

1) Executive Summary: First of all, the Executive Summary is generally the first section in a business plan. The Executive Summary is designed to be written last-don't write your Executive Summary first, write it last, primarily because if you wrote it first you would be changing it constantly. Here are some questions that you need to answer:

a. Does your Executive Summary convey to the reader that you have an understanding of what your business is?

b. Does your Executive Summary draw your reader in and say, "Read on so that you understand what we're about"?

c. Does it cover the most important points of your business plan?

d. Does your Executive Summary contain highlights of your enterprise-its products; its markets; the financial position; and its performance both current and objective? In a lot of cases we're going to be talking about a business plan that not only deals with historical fact (Where have you come from?), but what you're planning on, and this is one of the things that Elaine did was to build into her strategic plan a future. e. Does your Executive Summary contain knowledge of your industry, management team and the financial reports along with how you intend to make money and your fee structure? Elaine ticked through very quickly what her fee structure was, but as you heard it was a multi-tiered fee structure and that's especially important to keep in mind when you're trying to load your fee structure in such a way that you want to make money for your enterprise and for your laboratory. You also want to make sure that you aren't pricing yourself out of a market.

2) Vision: This is an interesting part of it and this is sometimes termed the "squishy part of it all." It's the visions, the missions and those kinds of things that again convey to the reader who you are and what you're all about. It should be reality based not grandiose; it should be focused and not too idealistic. The Managing Editor should be the initial author, but that doesn't mean there shouldn't be other collaborators in the development of the Vision Statement. Key members of the management team should have input. You can't lock the door on anybody that's working with the enterprise. It should lay out the path for the laboratory to stretch its possibilities; it should be simple, believable, achievable and understood. This is kind of a flip statement but, it's really kind of true, the best Vision Statement that you can have is to resolve to provide real products and services to real people who are going to buy them with real money.

3) Mission Statement: The Mission Statement, again, should describe concisely in writing the intended strategy and business philosophy for making the vision happen. This is the implementation of the vision:

Customers-who are they? Are they in-house or out-of-house?

Products and Services-what are they? How would you describe them?

Markets-where do you compete? Are there other laboratories like yours that you're going to compete in or with?

Technology - what are the basic technologies that you're trying to promote and sell?

Concern for Survival, Growth and Profitability - this is extremely important, especially in a highly dynamic environment where you're dealing with technology that is constantly moving and constantly developing, and you need to be in front of it. Otherwise, you'll be good for about a week and then after that you'll be left behind.

The Philosophy-what are the beliefs, values, aspirations and philosophical priorities of your laboratory?

Self concept - what are your major strengths and competitive/technological advantages?

Public Image-do you have the desire to be recognized in the public environment?

Employees-what is your concern for employees? These are highly trained and highly skilled individuals who come to work in your laboratories almost exclusively. Look to the care and feeding of these extraordinary people. They need that-trust me.

4) Goals: Again, these are some of the things that you need to put forth.

- Deal with vital issues (including strategic planning) in a timely manner

- Contribute to productivity

- Goals should be measurable and specific

- They need to be applicable to your Vision Statement and your Mission Statement

- They are ordinarily stated as end results. In other words, when we achieve our goal we will be "here" or we will have accomplished "this." 


\section{Multiphase Materials Characterization \\ Fully Integrated...Totally Seamless}

Powerful Analytical Tools Optimized for Your SEM to Provide Results with Confidence

- Pegasus...Simultaneous data acquisitions for EDS (chemistry) and EBSD (crystallography)Includes the patented Chl-Scan software to improve multiphase analysis capability

- Neptune...Complimentary union of EDS and WDS for superior X-ray microanalysis-Improves quantification especially for low level concentrations

- Trident...Ultimate materials characterization system integrates EDS, EBSD, and WDS with no analytical performance compromise-Provides complete solutions for all your materials characterization requirements

\section{Results with Confidence}

As the world's leader in Electron Beam Microanalysis, EDAX continues to raise the performance standard with innovative features that are easy to adapt and provides results that you can trust to be complete and accurate.

For more information on our Seamless Integrated Systems for EDS, EBSD, and WDS visit our web site at www.EDAX.com/integration or call 1.201.529.4880 Visit us at Pittcon Booth 4469

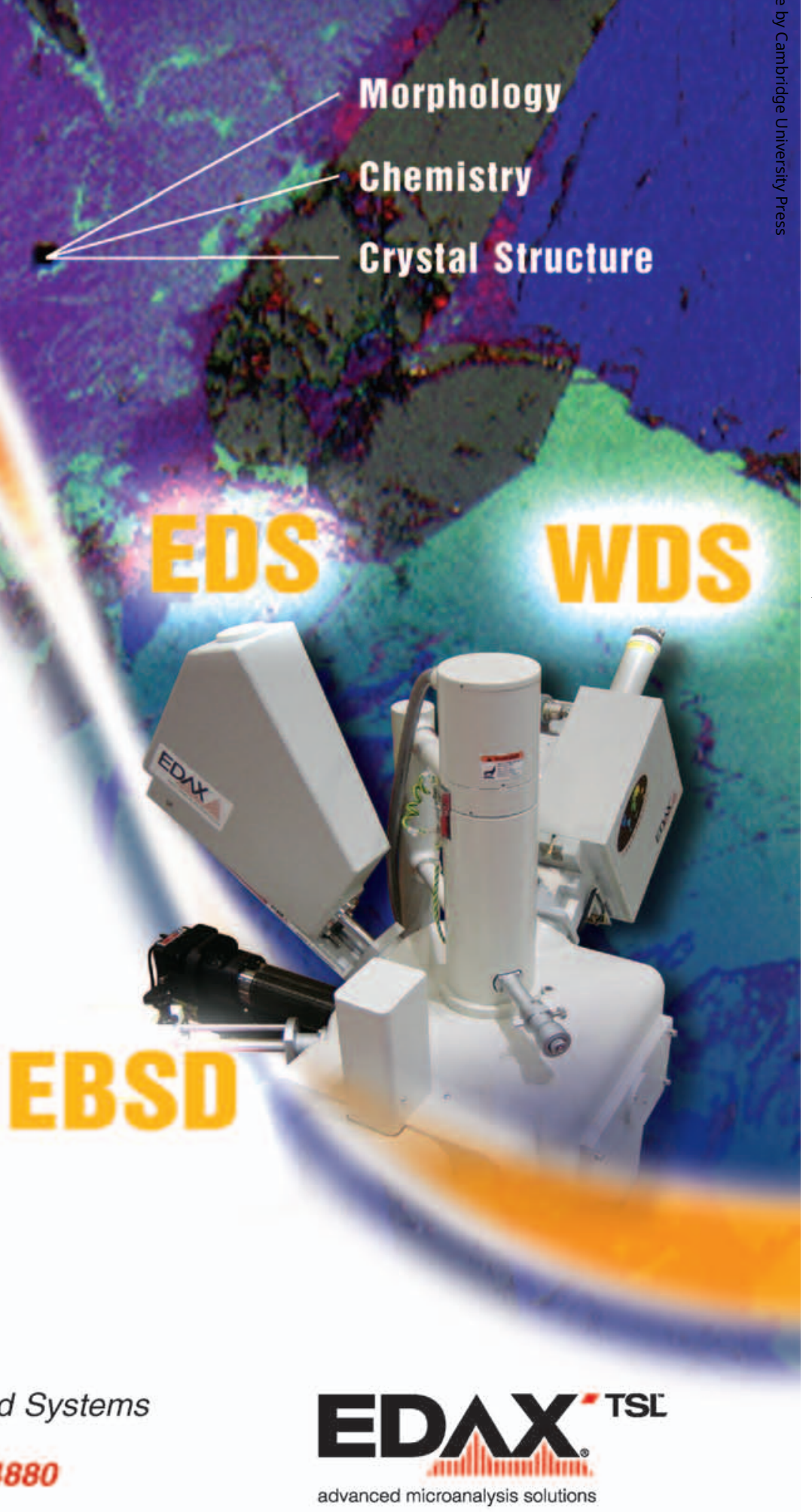

NMETEK 
- Offer challenges that are realistic

- Are controllable

- Are time limited

- Are rational

- Provide a return on investment. One of the things that you need to understand and continue to have out in front of you is that none of the stuff that we do is for free. There is always a dollar sign attached to it somewhere

- There needs to be a financial objective

- You need to be in a position in your business to grow

Goals can be chosen from such metrics as:

- Market penetration

- Market maintenance

- Market expansion

- Diversification

- Utilization of Capacity-is it your objective that you want to be $100 \%$ consumed in your capacity utilization?

- Financial performance

- Asset Productivity and return on investment-are extremely important

5) Enterprise Overview: One of the first few things that you would include in your Business Plan is an enterprise overview.

- What are your start-up costs? Have you already started up and now you're trying to expand the role of your laboratory and to do other things?

- What's your customer base? Who are your customers?

- Competition. Is there anybody in here that doesn't have competitors in their space? Everybody's pretty much got a competitor so you have to keep that in mind. You're not going to be out and about promoting the capabilities of your laboratory and do it in a vacuum.

- Business challenges. Who might replace your management team in the event of turnover, resignations, what have you?

- Pricing structure. What kind of pricing structure will ensure a healthy cash flow, overhead or burden?

- Industry trends. How might they change or affect the enterprise?

- Technology. What's the type and status of the technology, and how is it evolving? Extremely important, especially in a high tech area.

- Growth factors. A general statement about the economic health of the area and the business cluster in which you intend to do business.

6) Product Strategy: Things to keep in mind when you're dealing with product strategy and the strategic issues that are going on with your product:

- Are there any issues with your laboratory that require patent registration or copy writes?

- Do the capabilities of your laboratory and the resultant products and services meet your customer's needs and wants? This is extremely important. I don't care whether you're doing a notfor-profit or a for-profit, if you have dog food and the dogs don't eat it, then you might as well not have it.

- Does your business plan describe how your company will react to competition or a change in the market?

- Are there resources within your organizational that will allow you to do Research \& Development to continue to be on top of your game-to continue to supply equipment and techniques that are state-of-the art?

- When you're developing these new capabilities, do you refer back to your mission, vision, goals and objectives?

- Do you embrace a philosophy of continuous improvement for your competitive position, market value and price point? The continuous improvement mantra is something that is a hold-over of something that is fulfilled by the manufacturing sector in that you should be in a position to be continuously improving your processes, your people and all of the things that you offer in the way of products.

- Can you communicate your overall operations plan with respect to your products and services? One of the ways that you can do that is to continue to update your Business Plan.

- Do you know the cost of your product or service and can you include in that the cost of your burdens and overhead?

- Is there any latitude in fixing the location of your facility? In other words, are you where you want to be from a geography stand point or should you be somewhere else? I know a lot of cases of "it's not where I want to be, it's where I am."

- How will you deliver your end product to your customers?

- Are the principles of the laboratory readily accessible and responsive to your customers for problem resolution or information?

7) Market Analysis: A Marketing Analysis is also quite important.

- Have you conducted an industry analysis for your chosen, targeted industry?

- Have you conducted an analysis of the market within your industry?

- Have you identified the strengths and weaknesses of your competition?

- Have you determined how to turn the competition's weaknesses into a strength for your enterprise?

- Have you developed a customer profile-very important.

8) From that you can put together a Marketing Plan.

- How will the enterprise be positioned...vis-á-vis the competition...low cost?? Premium quality?? High volume??

- How is the price of the product/service going to be determined? Are you going to cost build-up? In other words, are you going to take the cost of what you're supplying and build that up into a pricing structure or do you go investigate the market and see what the price has been?

- Who are the customers??

- What type of advertising and promotion are planned? And this is extremely important_-advertising and promotion get the word out. If you have competitors you want to be more visible than your competitors are.

- How much money will be spent on advertising and promotion? I suspect some of your senior management says, "Aw, you don't need any of that!" I would suspect that they really don't have a good feel for what needs to be done. You need to have promotion and advertising whether it's a for-profit or a not-for-profit operation.

- Do public relations enter into your promotional plans? There are a lot of places where you can advertise the capabilities that you have by using public relations, and you can use it in a journal for instance, technical journals, and there are a lot of opportunities for that. (Don't forget Microscopy Today! ...Editor).

- Are there trade shows/expositions that will be worthwhile?? Cost of a display/booth??

9) Competition: Again, not to concentrate too much on the competition, but every enterprise is subject to competitive pressures...they can be sales/revenue oriented (competition for the product or service to be sold or delivered to the customer). They can be service oriented, in other words, you can have the same product but deliver it better. Sometimes the competitive pressures will come from within the organization as the enterprise competes for resources, primarily budget dollars. This will require that the 
management of the enterprise clearly understand how the enterprise can maximize the return on the investment.

Things to know:

- What are the competing technologies?

- What are the comparative features of the competing products and services?

- What is the competition's pricing structure?

- How is your competition organized... are they competent... will they try to steal employees... do they want to lead or follow in the market...do they have better funding than you have?

10) Risks: It is important to identify risks to the enterprise and then to put plans in place that will minimize the effect of that risk on the outcome of the business.

Potential Risks:

- The cost structure of your enterprise and the competitors

- Industry growth and growth of competitors within the industry

- Product/Service Liability...quality of performance-my hope is that we are all in this business to provide the best that we can.

- Profitability...planned $v s$. actual

- Dependence on complementary industries, suppliers, strategic partners

- Seasonality or business demand that is not level-this is something that will sneak up on you from time to time and you say, "Oops, we don't have level demand here." That's a negative effect on how you structure your business

- Vulnerability to substitution--in other words, will my customers substitute something else for my service?

- Limited number of suppliers to your enterprise-that could be a problem if you don't have a lot of suppliers in your enterprise

- Limited customer base-in a for-profit organization you really don't want to have a very small customer base because it doesn't take very much for you to lose all your business.

- Ability to retain trained personnel and/or hire new employees when required

- Economic Conditions

- Legal and Governmental regulations

11) Levels of the organization: Arguably, the most important element of the enterprise may be the people resources that populate it at all levels.

- Board of Directors...provides overall guidance and business direction... may be inside or outside the organization. Generally has overall fiduciary and legal responsibility for the enterprise.

- Board of Advisors... provides overall technical direction to the enterprise. Can be extremely important in obtaining certification of the laboratory.

- Managing Director...Chief Operating Officer

- Technical Staff... these individuals are generally charged with execution of the actual work.

- Administrative Staff...these individuals are responsible for the administrative functions that support the work of the enterprise (billing, purchasing, Human Resources, shipping, etc.)

12) Financial Plan: A Financial Plan is something that is extremely important because no matter what you do, you're still going to have dollar signs assigned to what you're going to be doing.

- You need to work closely with your business office to put together your Financial Plan.

- You need to be able to support that Financial Plan with financial statements.

- They are generally put together in three scenarios: best, worst and most likely.
- You need to maintain the worksheets that support your statements.

- The individuals involved in the operations and management of the enterprise need to understand the numbers.

- Generally speaking, you're going to be talking about monies associated with capital investment, but also you're going to be talking about dollars that are needed for the actual operation of the facility.

13) Exhibits: In the last part of your business plan, you put together Exhibits--anything that can support the elements of your plan including:

- Resumes for senior management and employees

- Letters of support from vendors and potential customers

- Copies of governmental regulations and/or description of work processes and results expected....are there ethical issues? Are there legal issues??

- Full description of quality initiatives and quality assurance manuals

- Copies of various planning documents including strategic planning

And again, as I mentioned, the interface between the Strategic Plan and the Business Plan could be the single most important interface that you put together.

Question: Could you give us some idea of what resources we should be using when we do our Market Analysis, particularly for a local region or area? Can you suggest some ways to start that?

Answer: The best place to start is your targeted customer-customers that you want to go after. You can call them up and say, "Look, what are you doing; how can we help you; in your industry, is your industry getting better/getting worse? That's one way to do it. Another way you can do it is to go to databases that are reflective of the industry that you are in, for instance Frost \& Sullivan is a database that is pretty comprehensive in a lot of areas, especially in high technology areas. So you have to be able to state "Here are all of the places where my particular technology, my equipment and my ability to perform work has an effect; these are things that I can do." From there you can branch out and not only ask questions of people that are in the industry, but also go to other databases that could be very helpful. If you're located on a university campus go to your library and say, "Here's my problem. I need to find out all I can about this industry or that industry or this application or that application," and you'd be surprised. They could probably come up with a lot of things that would be very, very interesting that tells you not only what you can do, but how much of it you can do; and that's what you're really looking for.

Participant comment: I just want to speak to that point in terms of practical usage for university central labs, and that is to have a good relationship with your user group and have the support of your user group for improvements or additions to your laboratories. Make sure you know them and they know you and keep them involved. It's a very strong support for your laboratory if you can get them to speak as a single voice to the administration. They're the people bringing in grants and indirect costs, which is what the administration is looking for to pay the bills.

Don Blewett: Cost sharing is extremely important in the university environment and I echo that. Anytime you come up with some grant opportunity that could cost share to a number of departments, you're a hero.

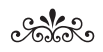

